\title{
Summary of Transient High-Voltage Calculations for the FRX-C Experiment
}

\author{
R. W. Kewish, Jr.
}

D. J. Rej

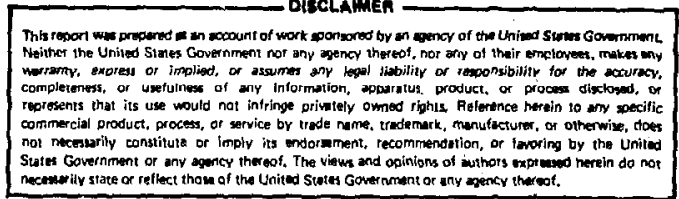

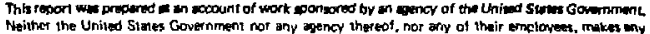

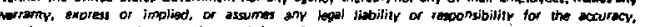

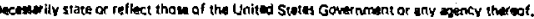

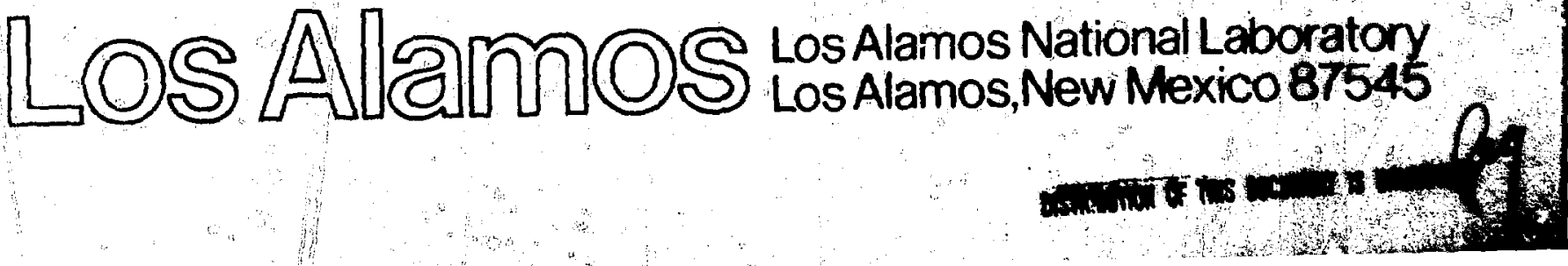




\title{
SUMMARY OF TRANSIENT HIGH-VOLTAGE CALCULATIONS FOR THE FRX-C EXPERIIENT
}

by

R. W. Kewish, Jr., and D, J. Rej

\begin{abstract}
Calculations of the electrical circuit equations are performed over a wide range of parameters corresponding to the FRX-C field-reversed $\theta$-pinch experiment at Los Alamos. Without any plasma or external damping, serlous voltage doubling and quadrupling of the rain capacitor bank charge voltage are observed. These osclllating high voltages are found to be adequately suppressed by the strategic placenent of external "snubber" clrcuitry. On the other hand, no doubling of the $\theta$-pinch preionization bank charge voltage is found. Calculations of the equations for the z-pinch prelonization circult are also performed.
\end{abstract}

\section{Introduction}

In an effort to determine and suppress any transient high voltages, calculations of the electrical clrcult equations were performed corresponding to the parameters of the FRX-C device. ${ }^{1}$ The code Mint-Sceptre, ${ }^{2}$ avallable on the Lawrence Livermore National Laboratory MFE - CDC-7600 computer, was used for these numerical evaluations.

The equivalent circuit used in these computations is shown In Fig. 1. In view of the near-symetry of the FRX-C dual-feed system, this circuit represents only one-half of the respective main and $\theta$-plnch prefonization capacitor banks, cables, collector plates, bias field clrcult, and load. Average values of the respective clrcult parameters are 1/sted In Fig. 1. The low-voltage blas magnetic field capacitor bank clrcult could be neglected because it is normally crowbarred during the high-voltage bank operation. Each transmission line (consisting of parallel coaxial cables) was represented as five discrete capacitors and $1 \times$ inductors. (Doubling these numbers of discrete elements made no noticeable changes in the computed voltages and 
currents,) Any coupling to the discharge plasne was neglected, and the only damping considered was that caused by external "snubber" c1rcultry; therefore, these resulte represent "vacuun" or worst cases were transient voltages are not suppressed by the plasme.

Adjustable paraneters in these calculations included (sef F1s. 1) : (1) bias Inductor nubber parameters $R_{B s}, L_{B g}, C_{B_{g}} ;(2)$ collector plate resistive damper elenents $R_{D}$, $L_{D}$; (3) nain-bank snubber paraneters $R_{X}, L_{X}, C_{x}$. The results are arranged into three sections consieting of studies of the min capacitor bank, $\theta$-pinch preionization (PI), and $\mathrm{z}-\mathrm{p}$ inch $\mathrm{PI}$, respectively.

II. Main-Bank Studies

F1gure 2 shows results corresponding to the case where the main bank is discharged at $42 \mathrm{kV}$ and where the $\theta-\mathrm{PI}$ bank 1s fully diacharged with apark gaps closed. (No qualitative differences appeared when PI gapa were considered open.) For this case, no snubbers or damping resistors vere considered, so these results represent FRX-C operationsl conditions before January 1982. As seen from this figure, the load coll voltage "rings" at approximately $3.1 \mathrm{MHz}$ (resulting from cable pulse charging), often doubling the original charge voltage. Further doubling ( $\sim 150 \mathrm{kV})$ occurs acrose the bias 1solation Inductor; this effect probably caused the observed high-roltage breakdown fallures at the cable feeds to this inductor.

During January 1982, four onubbers, each consisting of a 0.05- $\mu f$,

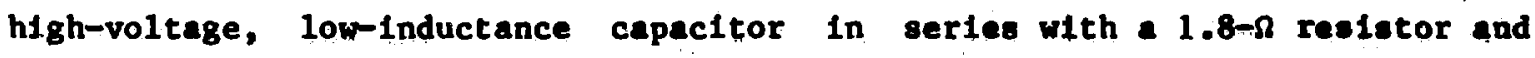
with a total self-inductance (after Installation) of approxinately $80 \mathrm{nh}$, were Installed acrose the bias inductor. Results from calculations for this situation are shown In F1g, 3, "As seen from these graphs, the blas snubber successfully danps out the recurrent osclilations shown in Fig. 2, both on the bias Inductor as well as on the load col1. A peak current per anubber of approxinately $20 \mathrm{kA}$ flowe for about $100 \mathrm{nsec}$ with a total energy 1 eas than 200 $J$ deposited. The first voltage peik nay be reduced with additional parallel snubbers (e.8., see $\pi \mathrm{H} .4$ ) at the expense of persietent oscillatione acrose the load coll.

Further reductione (although lees dramatlc) of the Initial voltage oscillation could be achieved by adding snubbers acrose the malm-bank capacitore. For exenple. Fige. 5a-d show the load coll and bias inductor 
voltages when 10\%, 25\%, 50\%, and $100 \%$ of these capacitors each have a $0.05-\mu f, 3.6-\Omega, 80-\mathrm{nH}$ snubber across then. These snubber values were considered because they were "tuned" to danp out the calculated oscillations; furthermore, a sizable quantity of these components $(\sim 300)$ has already been procured by CTR division and night be made avallable for use on FRX-C, if necessary. The total snubber currents and deposited energles for these cases are shown in FIgs. 6a-d.

The effect of a danping resistor $R_{D}$, perhaps consisting of a conducting rubber linking the edges of the collector plates, was also considered. Including the existing blas inductor snubber, Fig. 7 shows results for $R_{D}=$ $0.7 \Omega$. Unfortunately, this represents a lower lintt on $R_{D}$, since lower values will conduct more than $10 \%$ of the $\theta$-pinch PI current.

The effect of main-bank fitter is shown in Figs. 8a-d where the discharging of $10 \%$ of the main bank was delayed 50,100, 200, and 500 nsec, respectively. For these calculations, only the actually installed blas snubbers were included. Figs. 9a-d show the sane type of plots if $25 \%$ of the main bank fired late. The persistent oscillations observed In Figs, 8 and 9 were significantly decreased by adding the $0.7-\Omega$ danping resistor $R_{D}$ (e.g., see Fig. 10a); however, the addition of the above-mentioned snubber circuits to the entire main bank was much 1 ess effective (Fig. $10 \mathrm{~b}$ ).

To justify the use of the "half" clrcult nodel (F1g. 1), a limited number of calculations were performed using the full FRX-C electrical circult shown In Fig. 11. The near-gymetry of this circult is reflected in Fig. 12, corresponding to the case where the complete main bank 18 discharged. In F1g. 12a, voltages across the load colls LLT and LLW (see FIg. 11) and both blas Inductors are plotted for the case with no external damping. The effect of the normal bias Inductor snubbers ( $R=0.45 \Omega, L=20 \mathrm{nH}, C=0.2 \mu \mathrm{F}$ across each Inductor) on these paraneters 18 shown In F1g. 12b. The fitter problen assoclated with one side of this bank discharging late was also Investigated and no further voltage enhancements were found.

III. Q-PInch PI Studies

Calculations were also perforned for the discharging of the $\theta$-pinch PI bank. Flgure 13 shows results when no snubbers or danpers were considered. (Again, this case corresponded to FRX-C operation conditione before January 1982.) For th1s case, the PI benk was discharged at $55 \mathrm{kV}$ and the main bank 
was charged to $42 \mathrm{kV}$ with spark gaps continuously open. Both the absence of voltage doubling and the relatively low frequency osciliations $(1.0 \mathrm{MHz})$ are Indicative of the large capacitance arising from the 420 main-bank cables also connected across the collector plate. The effect of the bias inductor snubber (1.e., current operational conditions) is shown in F1g. 14. Further calculations for a varlety of snubber and damper resistor values showed no high-voltage transients.

IV. Z-Pinch PI Studies

Some brief results are presented from analyzing the FRX-C Z-pinch PI circuit (see Fig. 15). Mini-Sceptre was especially suited for these analyses, since it allowed the proper dependence of resistance on current for the varistor stack as well as a delayed breakdown time of the plasma. Sample results are presented in Fig. 16 for the case with $45-\mathrm{kV}$ bank voltage and a very low resistance plasma (compared with the inductive reactance). The effect of delayed plasma breakdown is shown' in Fig. 17. Each curve corresponds to a separate calculation where the plasma resistance was decreased from essentially infinity to zero in 1 nsec at times up to $12 \mu s e c$ after triggering the z-pinch capacitor bank. The observed decreasing plasma current with later breakdown time is a consequence of the increasing fraction of the capacitor bank discharged through the $3.1-\Omega$ shunt resistance.

\section{Conclusions}

Calculations were performed of the FRX-C circuit equations for the main capacitor bank, $\theta-p I n c h$ PI, and Z-pInch PI systems. Serlous voltage doubling and even quadrupling of the main-bank charge voltage were observed for vacuum shots when no external snubber or damping circuitry was considered (corresponding to the experimental sttuation before January 1982). The addition of blas inductor snubbers, installed on the experinent in January 1982, resulted in the successful damping of the calculated enhanced oscillating voltages both at the blas inductor and the load coil. Although further suppression of the initial oscillations could be achieved using Individual snubbers across fraction of the main-bank capacitors, it is not recommended at this time in view of the sizable cost and nachine dointire required. However, if bank jitter appears to be a serious problem, 
collector-plate-danping resistor could prove very useful in suppressing calculated persistent oscillations.

Calculations of the $\theta-\mathrm{PI}$ circuit equations resulted in no observed voltage doubling, even without any snubbing or damping circuits. Thls was a result of the relatively low-impedance main-bank cables located across the collector plate.

Mini-Sceptre also proved useful in analyzing the $Z$-pinch PI circult. For example, it could handle plasma breakdown time variation as well as the varistor $R(I)$ dependence.

\section{Acknowledgments}

The authors would like to thank J. G. Melton, J. C. Cochrane, and R. K. Linford for their earlier calculations, assistance with the computer codes, and useful discussions of the current results.

\section{References}

1. W. T. Armstrong, R. R. Bartsch, J. C. Cochrane, R. W. Kewtsh, M. Haworth, R. K. Linford, J. Lipson, K. F. McKenna, D. J. Rej, E. G. Sherwood, R. E. Siemon, and M. Tuszewsk1, Proc. Fourth Symp. on the Physics and Technology of Compact Toroids, Lawrence Livermore National Laboratory, 1981.

2. H. W. Carter, "Mini-Sceptre A Computer Program for Electronic Circuit Analys1s," Lawrence Livermore Laboratory report UCID-30069 (1973). 


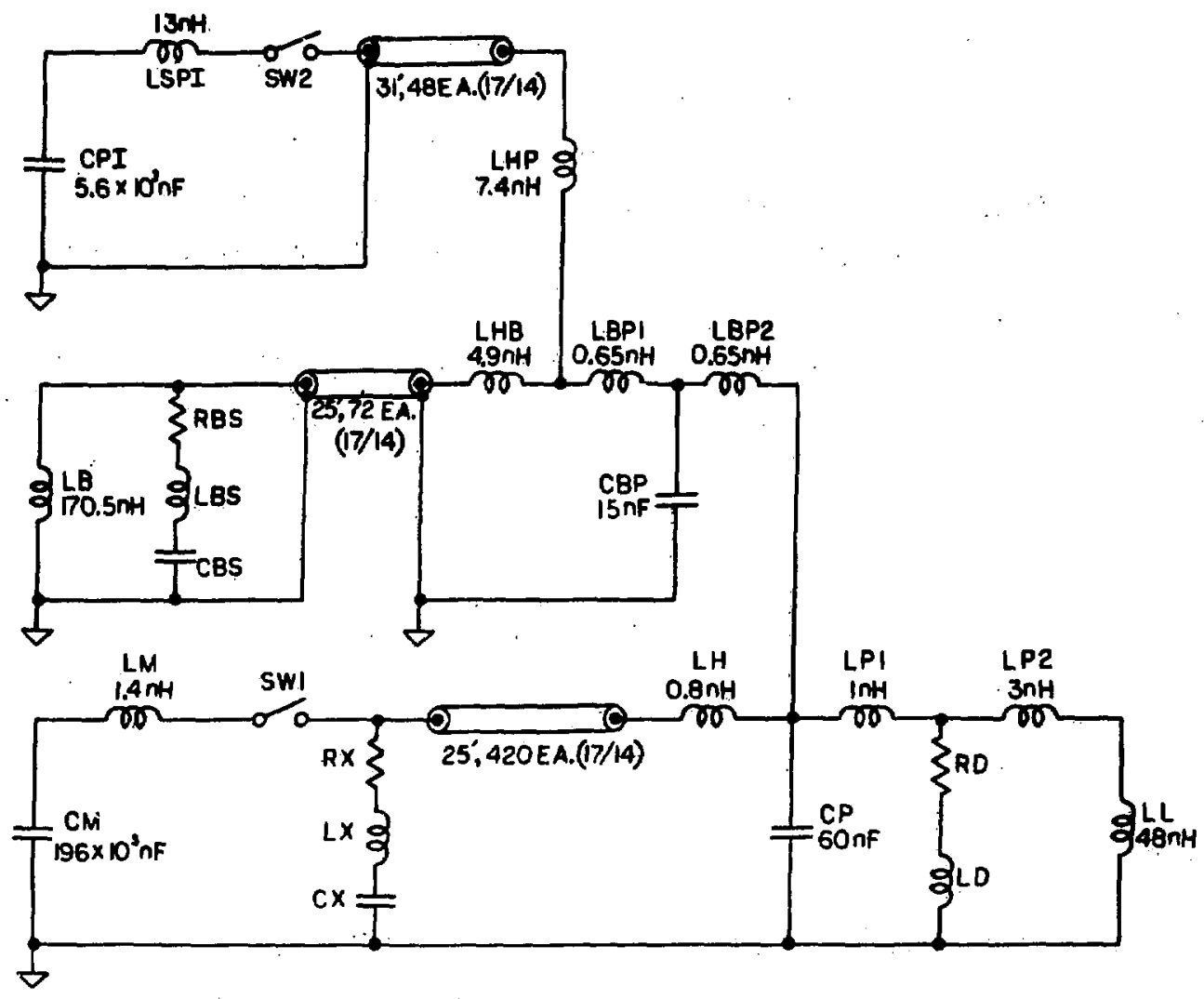

\section{LEGEND FOR FIGURE I}

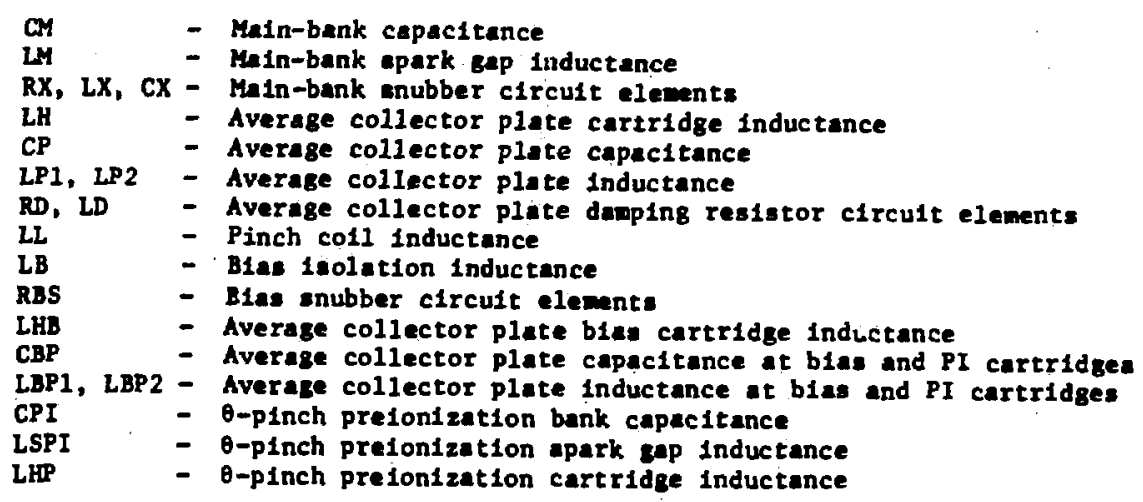

F1g. 1. Schenatic diagran of circuit used in these calculations. 

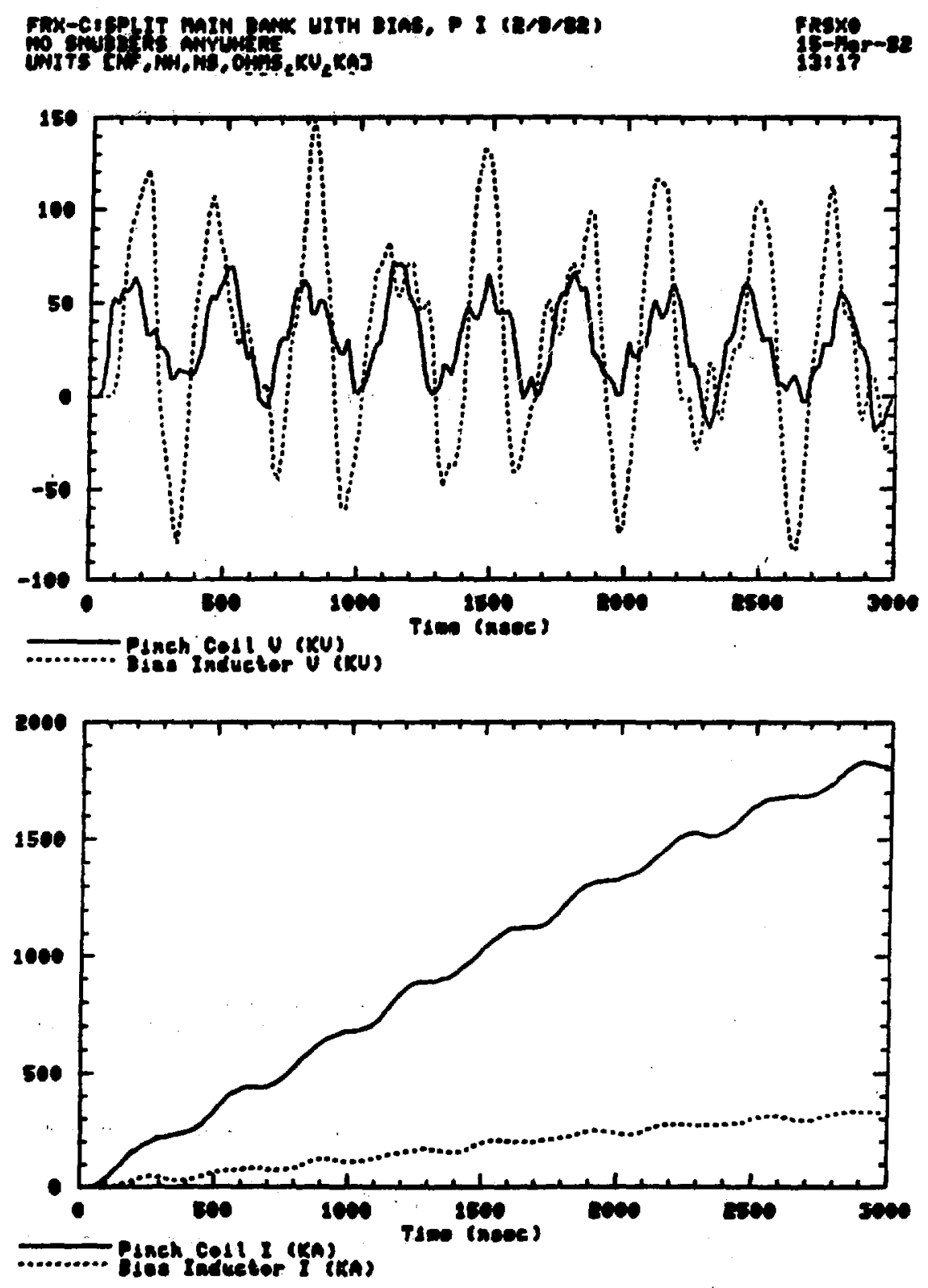

F1g. 2. Loed coll and ties inductor voltages and currents calculeted for a 42-kV main-benk flecharge with no enubbers or danping resistors. 

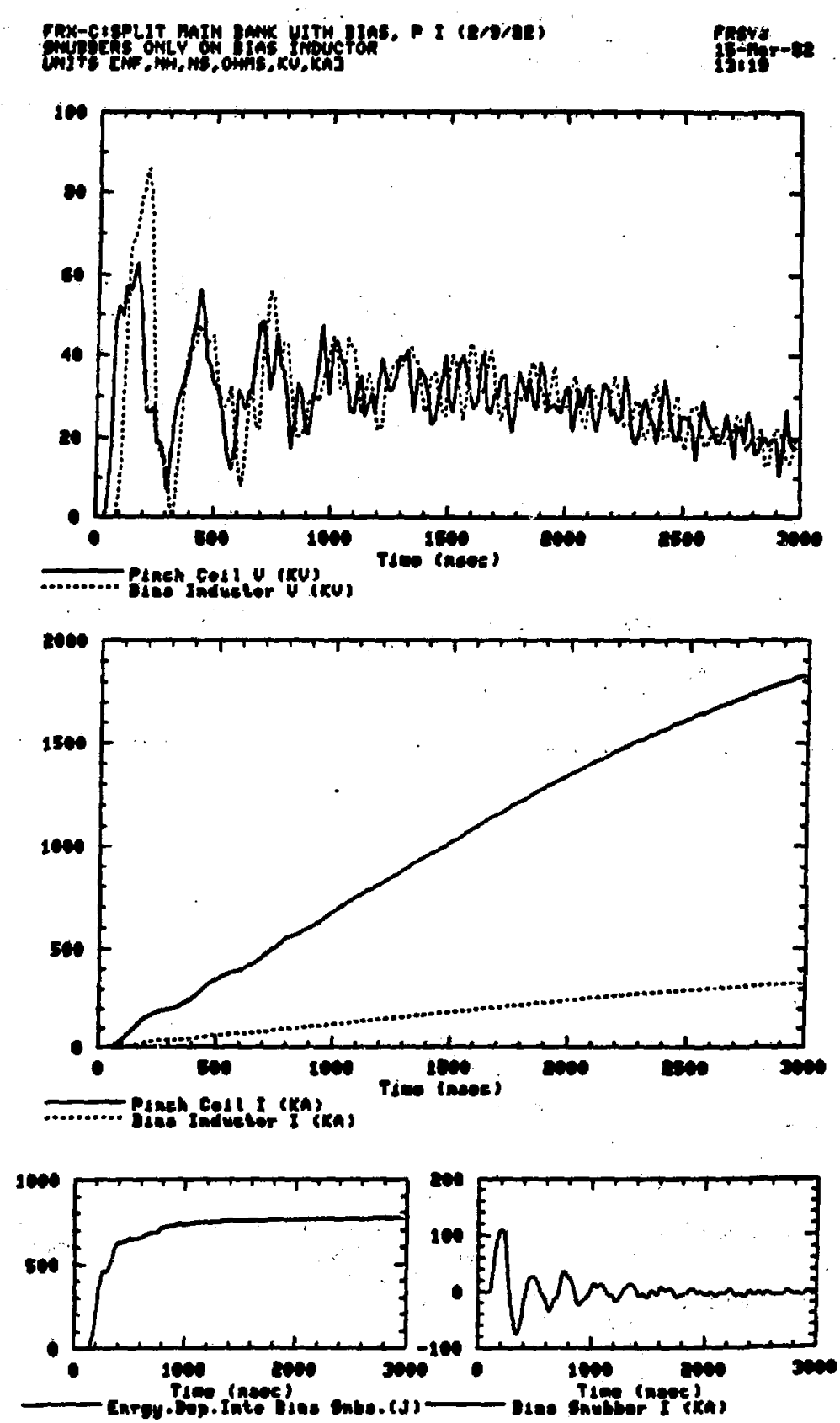

F18. 3. Voltages, currents, and total deposited energy calculated for a 42-kV anin-benk discharge with a $0.45-\Omega, 0.2-\mu F, 20-\mathrm{nh}$ smubber placed across the bias 1solation inductor. 
FRX-CISPLIT MAIN DANK UITH IIAS, P I (2/9/82)

NO SNUSS ON MB BIAS SNUR ReO.1IES OHM

UNITS CNF, NH, NS, OHMS, KU,KAJ

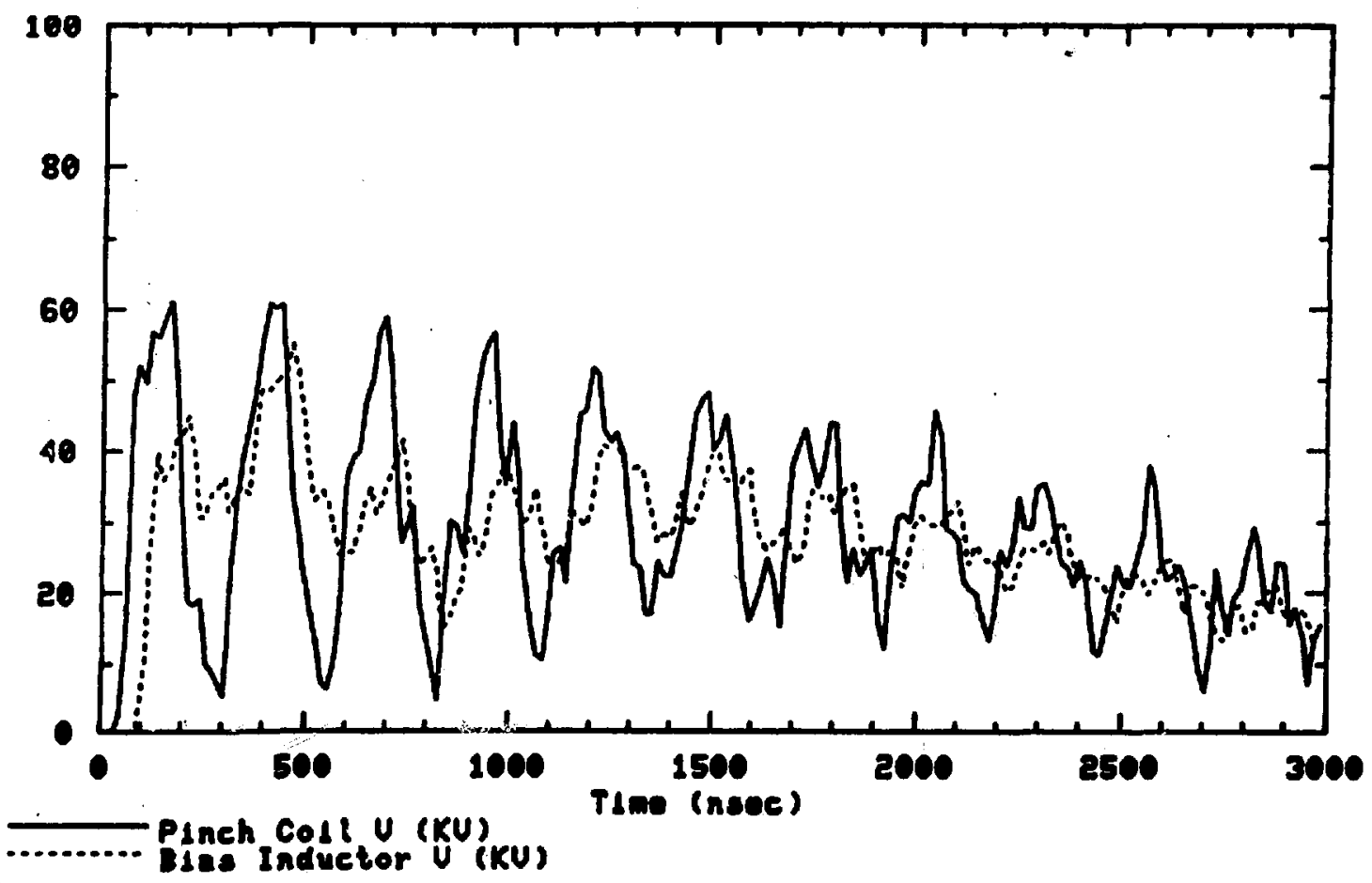

F1g. 4. Voltages calculated for a 42-kV anin-bank diacharge with a 0.113- $\Omega$, $0.8-\mu F, 5-n h$ blas inductor snubber. 
a)
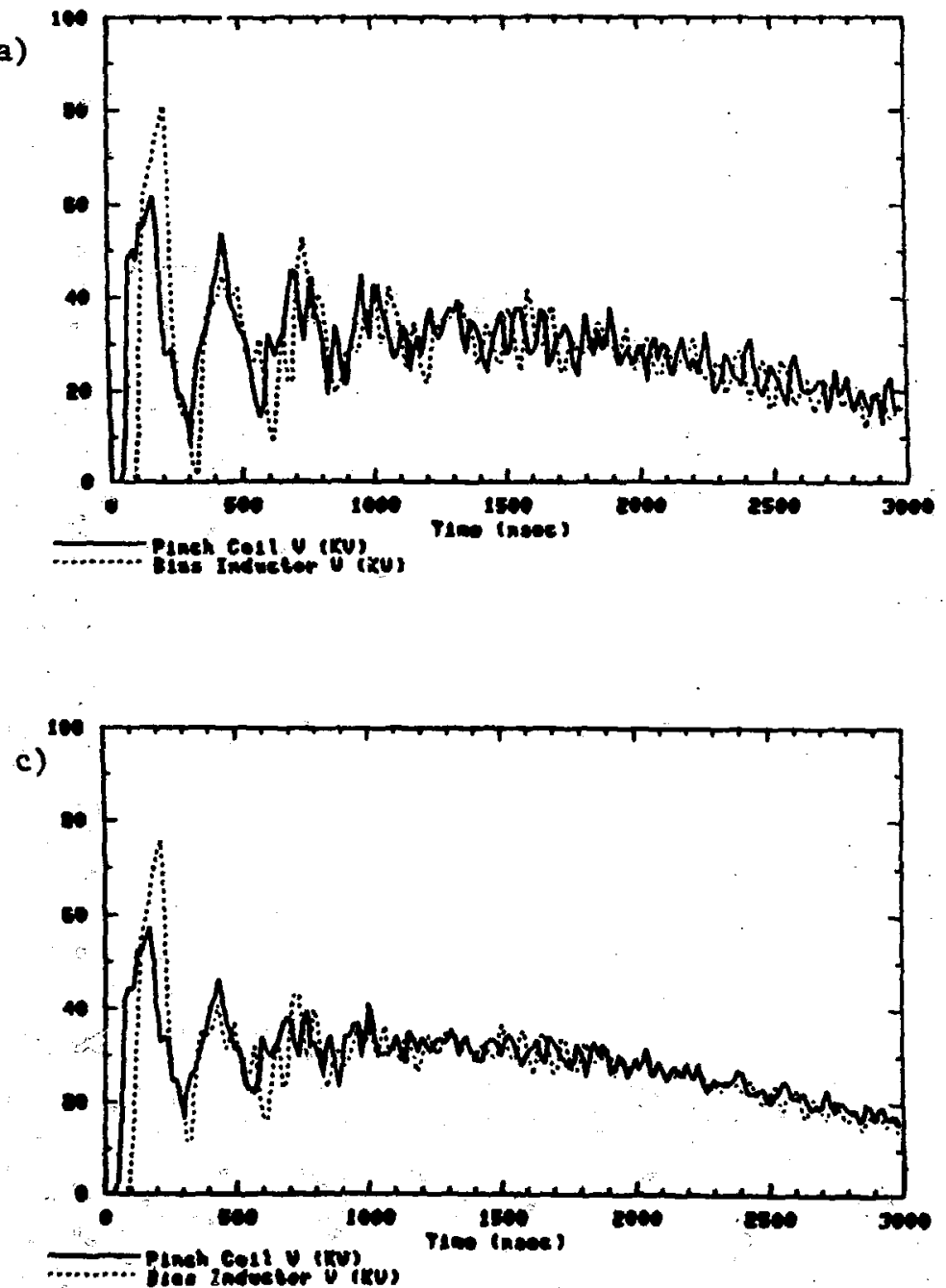

b)

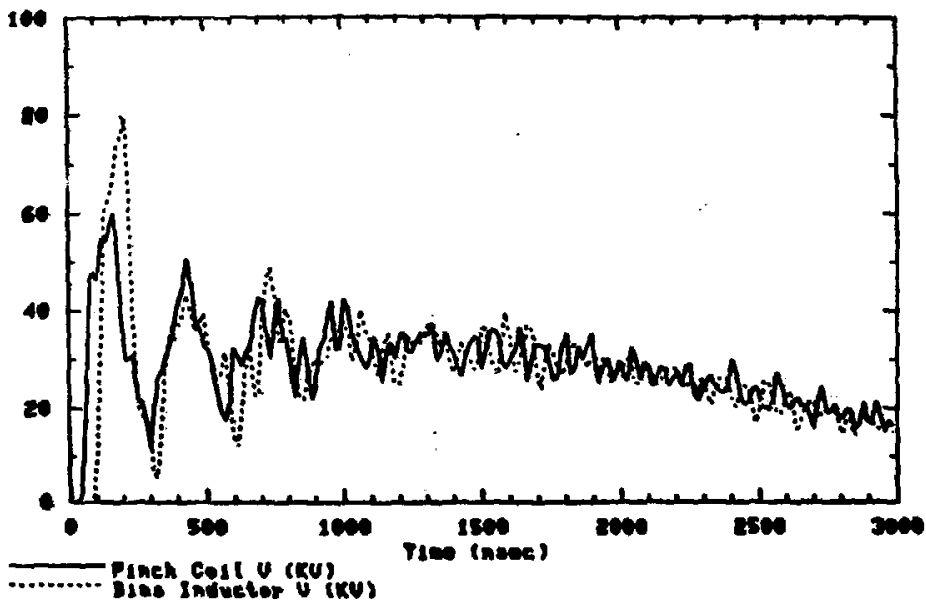

d)

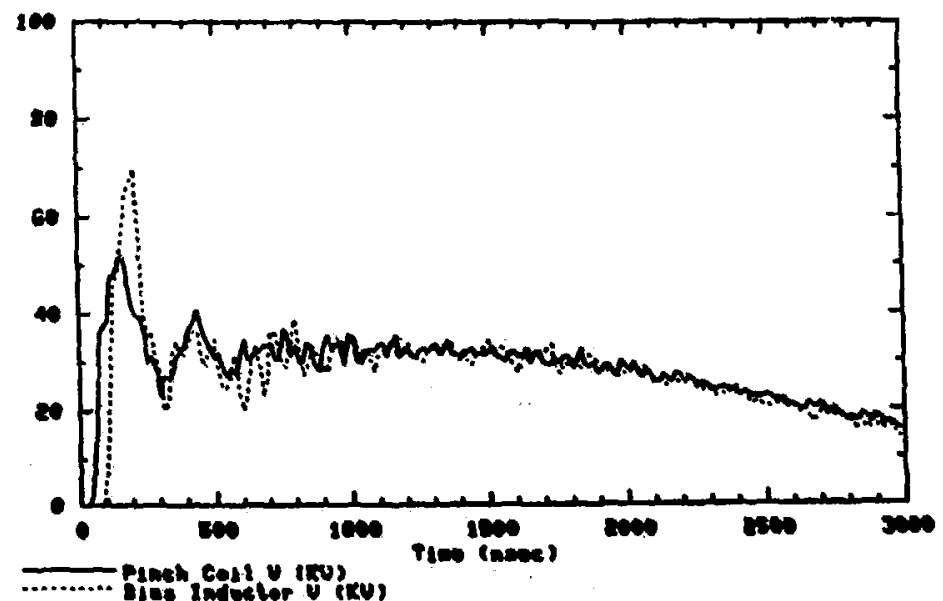

118. 5. Effect of main-bank snubbers: voltages calculated when a) $10 \%$, b) $25 \%$, c) 50\%, and d) $100 \%$ of the maln-bank capacitors are each equipped w1th $3.6-\Omega, 0.05-\mu f, 80-n H$ snubber; $0.45-\Omega, 0.2-\mu \mathrm{F}, 20-\mathrm{nH}$ snibber is also across the blas Inductor. 
a)
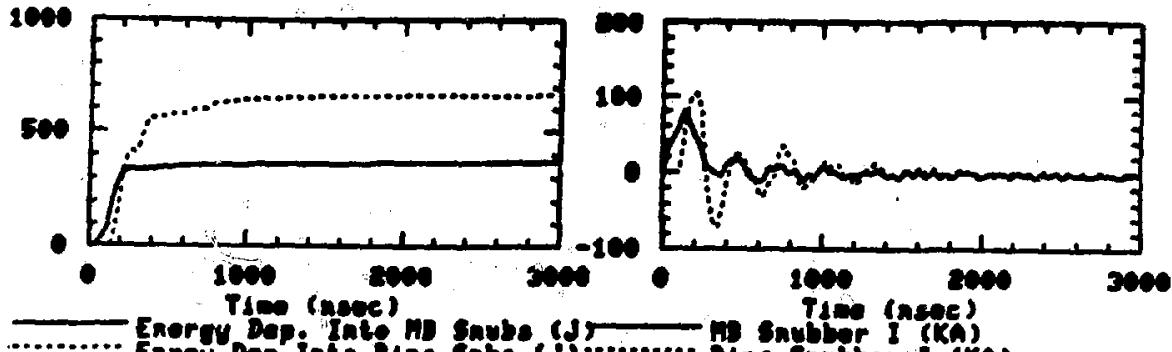

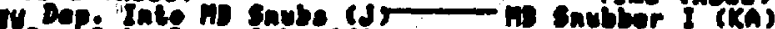

Enrgy.Dos.ince bias Snbe.(J)......... Diles Saubler I (KA).

b)
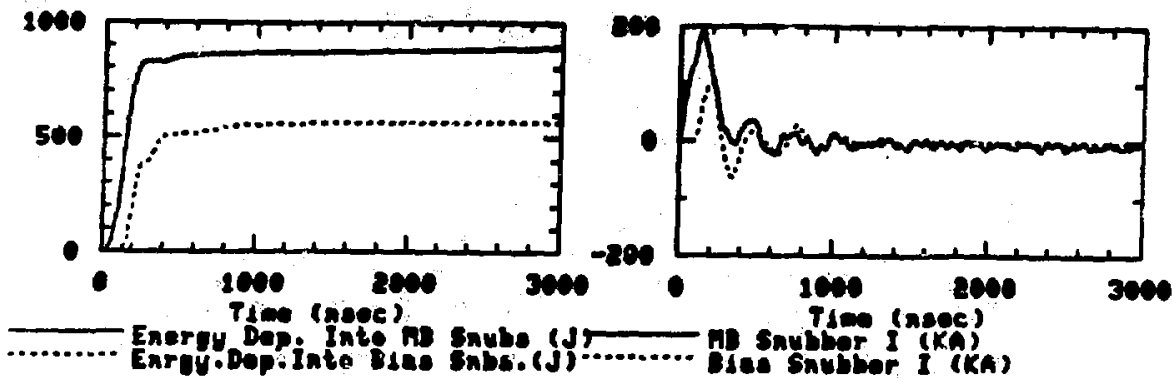

c)
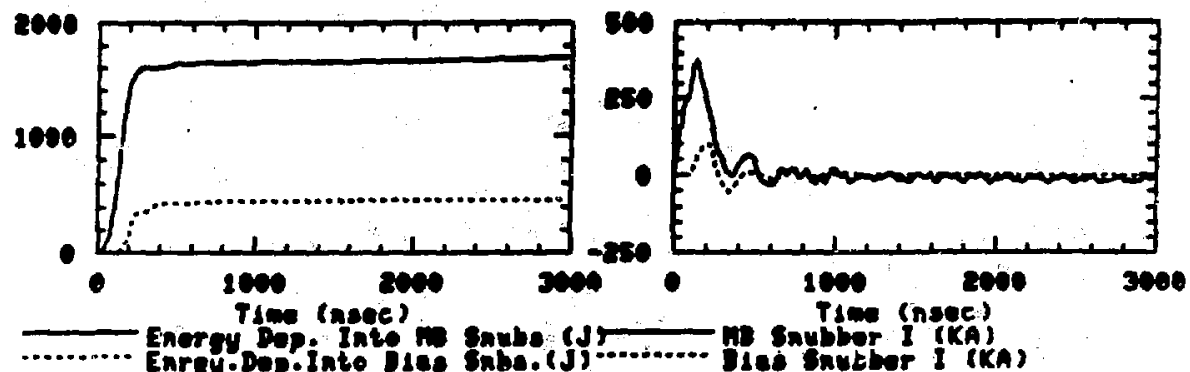

d)
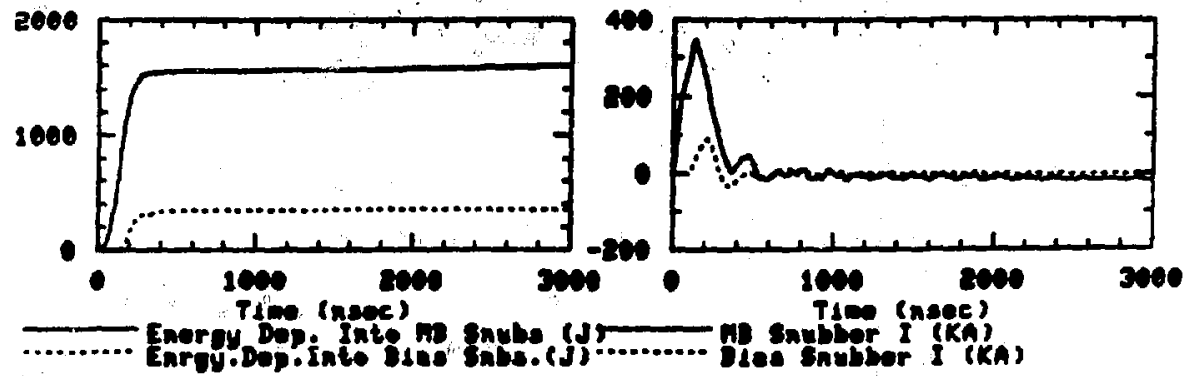

Fig. 6. Bias and main-benk subber energies and currents for the cases where a) $10 \%$, b) $25 \%$, c) $50 \%$, and d) $100 \%$ of the anin bank is equipped with 


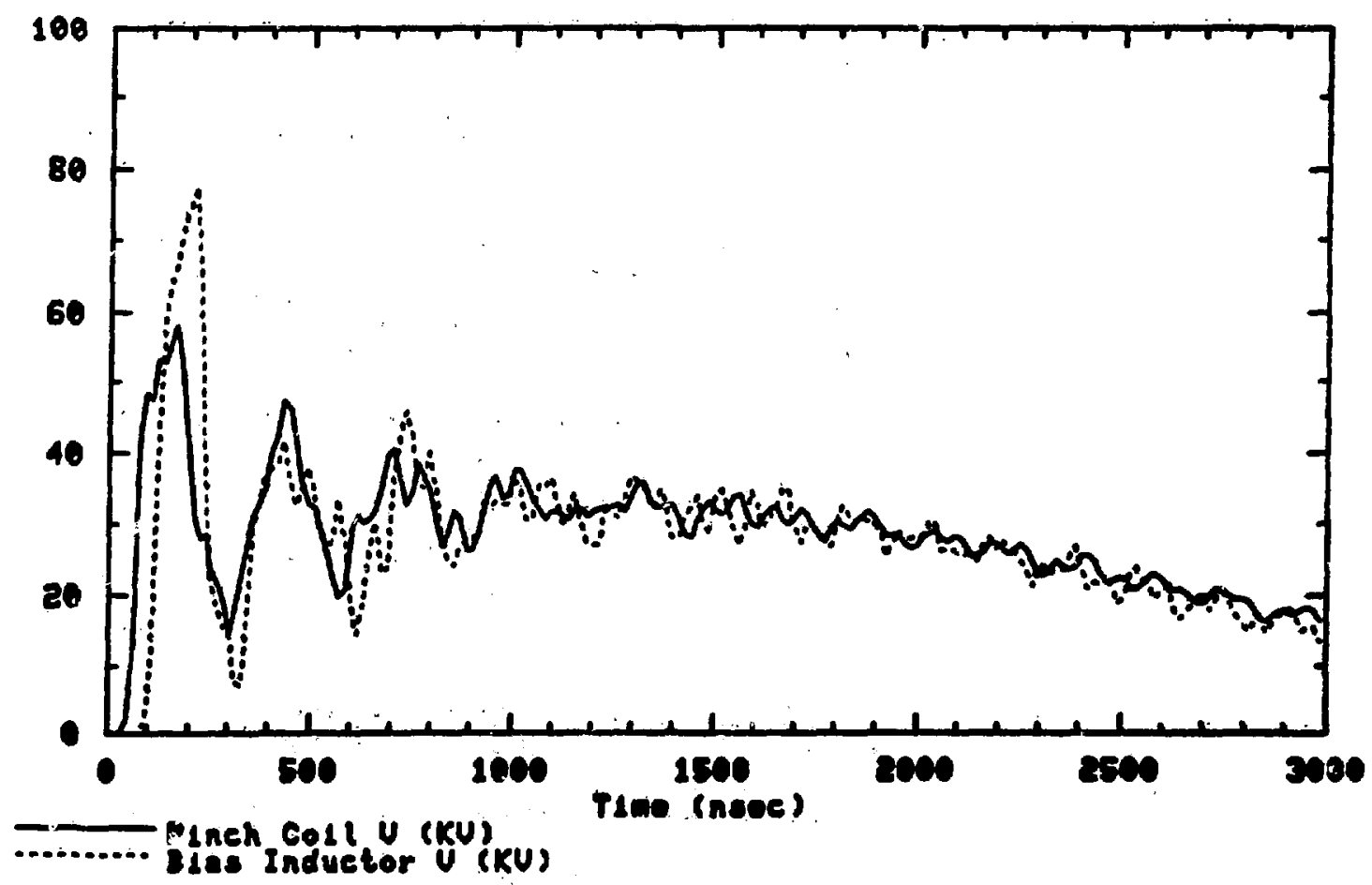

F1g. 7. Effect of $0.7-\Omega$ "danping": resistor placed across collectos plates. The normal bias inductor snubbers are also included. 
a)

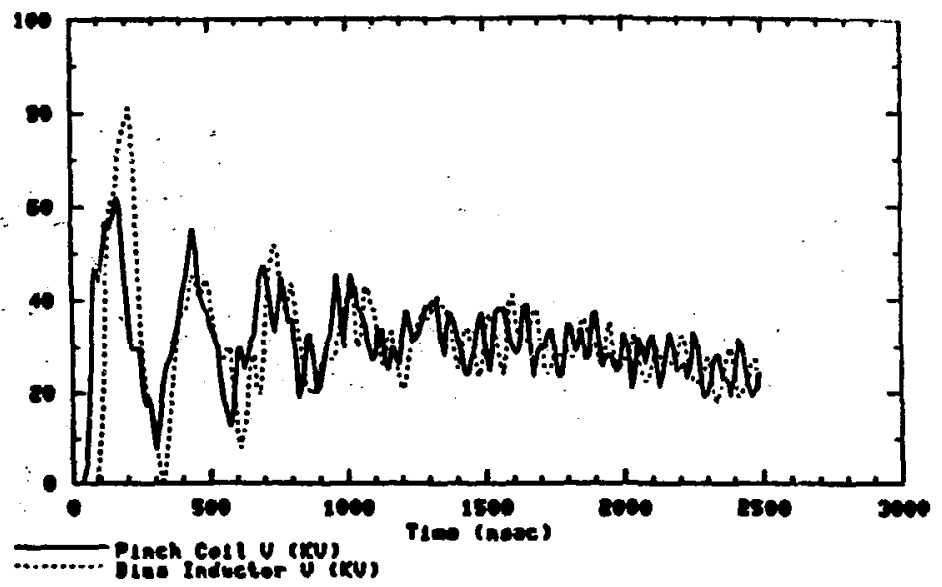

c)

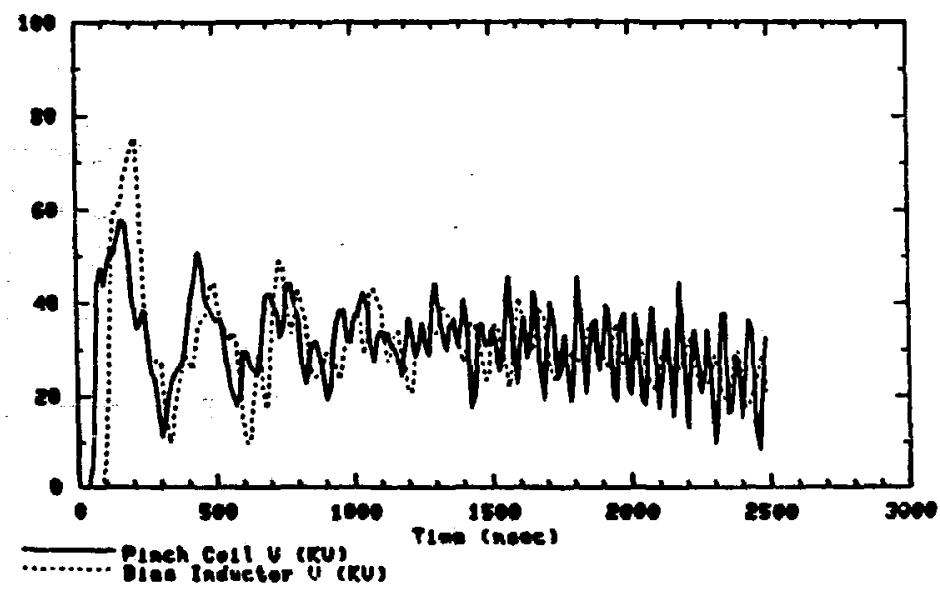

b)

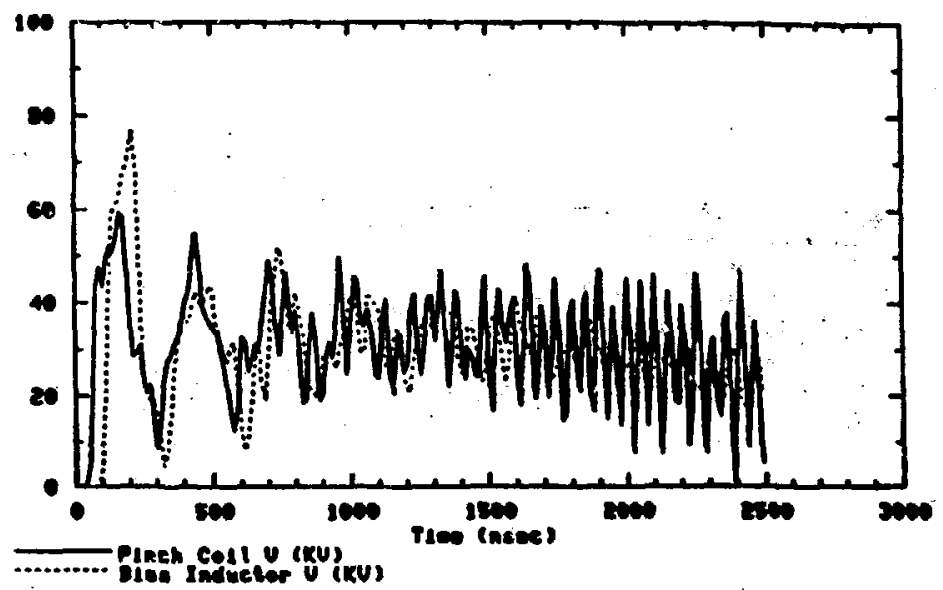

d)

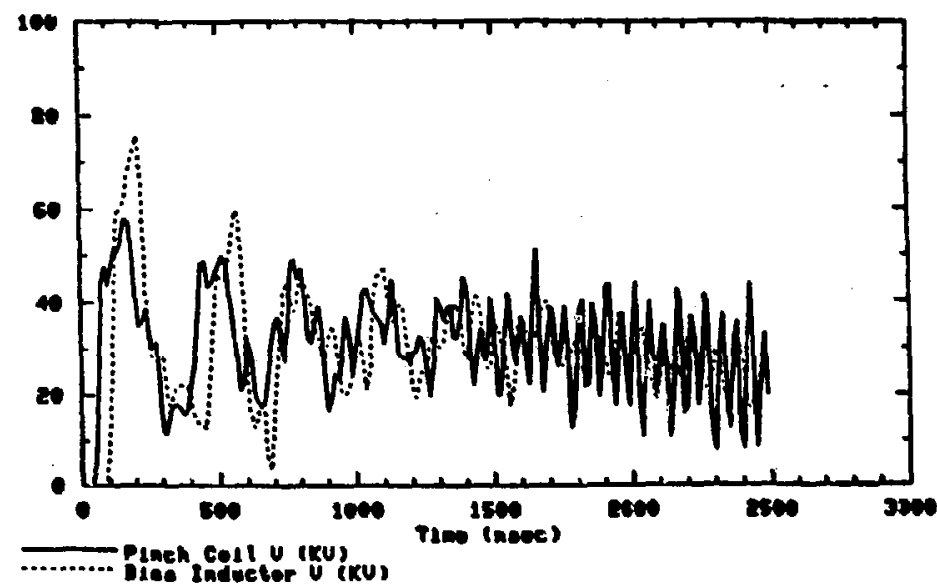

F18. 8. Effect of main-bank jitter: calculated voltages for cases when $10 \%$ of the main bank d1scharges a) 50 , b) 100 , c) 200 , and d) 500 nsec late. 
a)

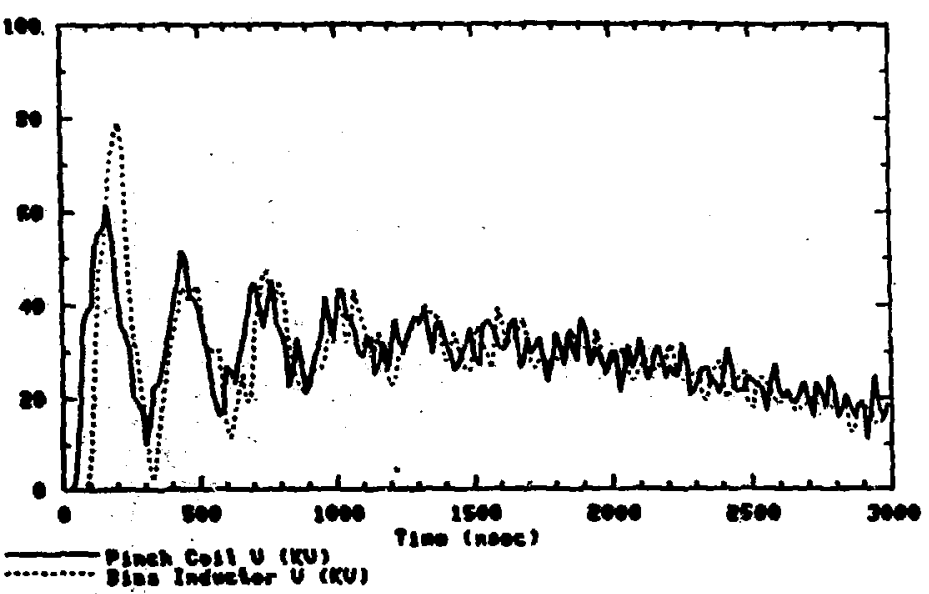

c)

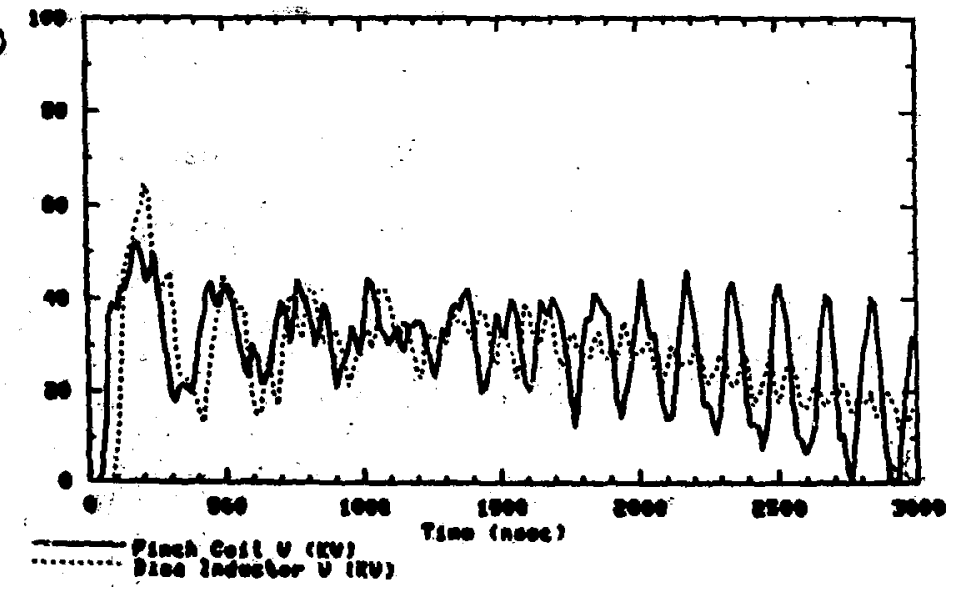

b)

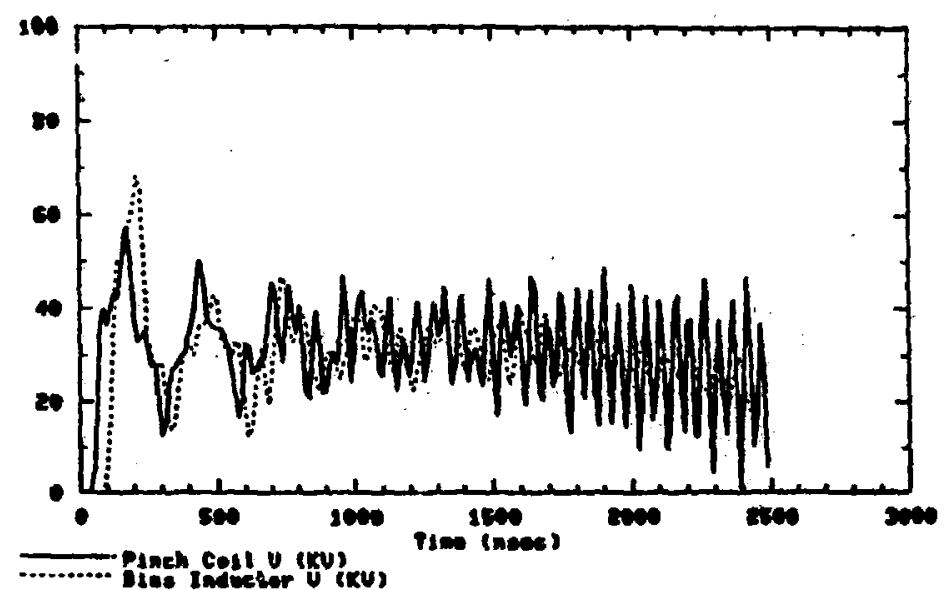

d)

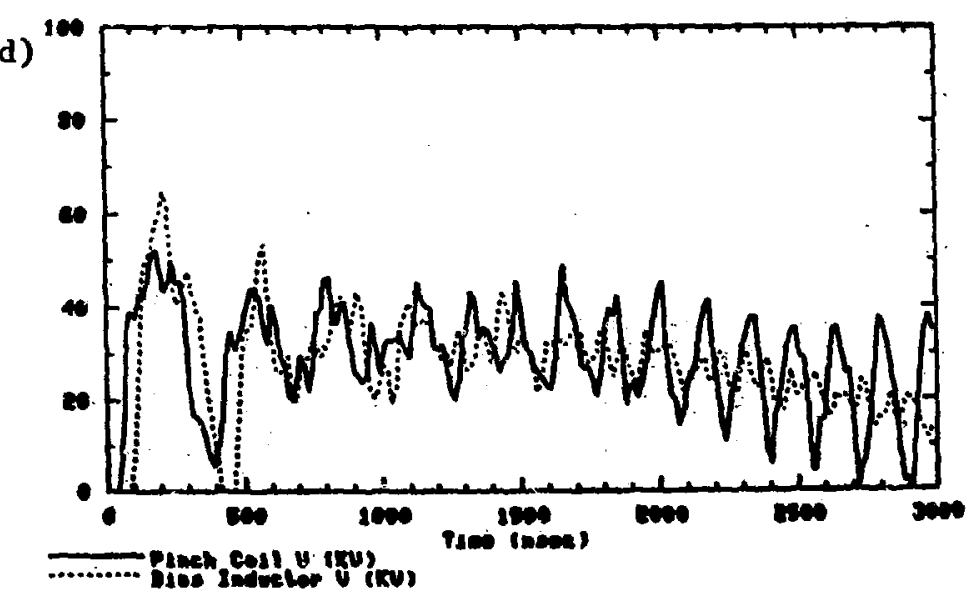

F18. 9. Calculated roltages for the cases when $25 \%$ of the wain bank discharges a) 50, b) 100, c) 200 , and d) $500 \mathrm{nsec}$ late. 
a)

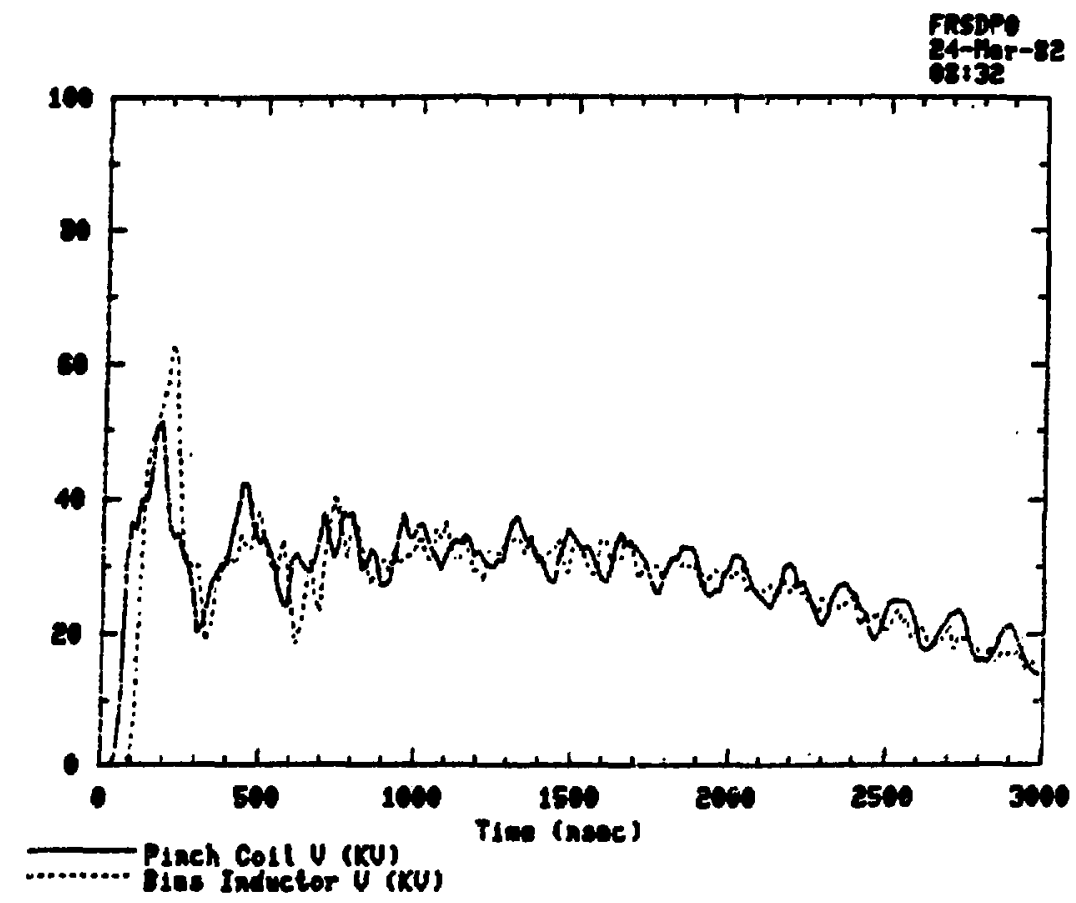

b)

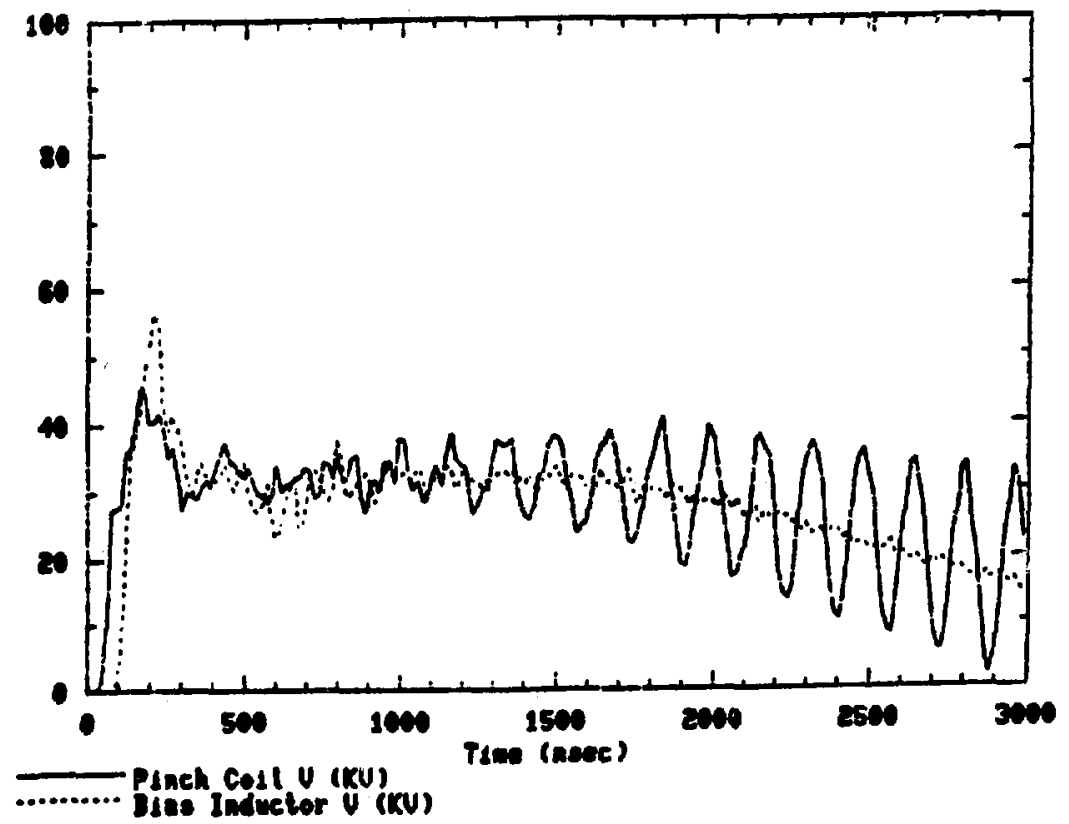

F18. 10. Calculated vol sages for the case when 257 of the anin bank discharges 100 nsec late: a) 0.7-n damping resistor added; b) each anin-bank capacitor equipped with $23.6-\Omega, 0.05-\mu F, 80-n h$ enubber. 


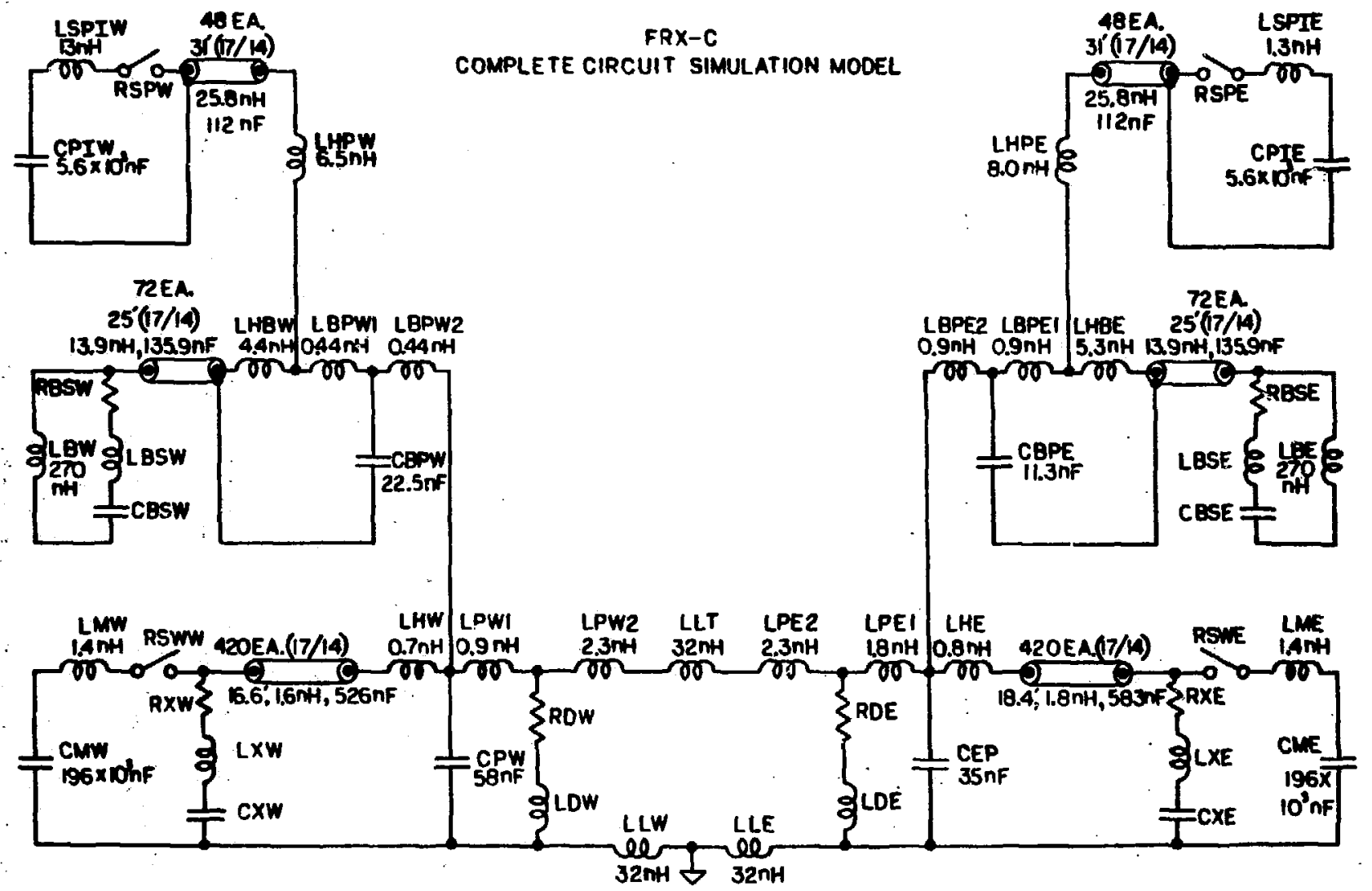

18. 11. Schenatic diagran of c1rcuit used in full IRX-C circult capacitor benk celculations. 
a)
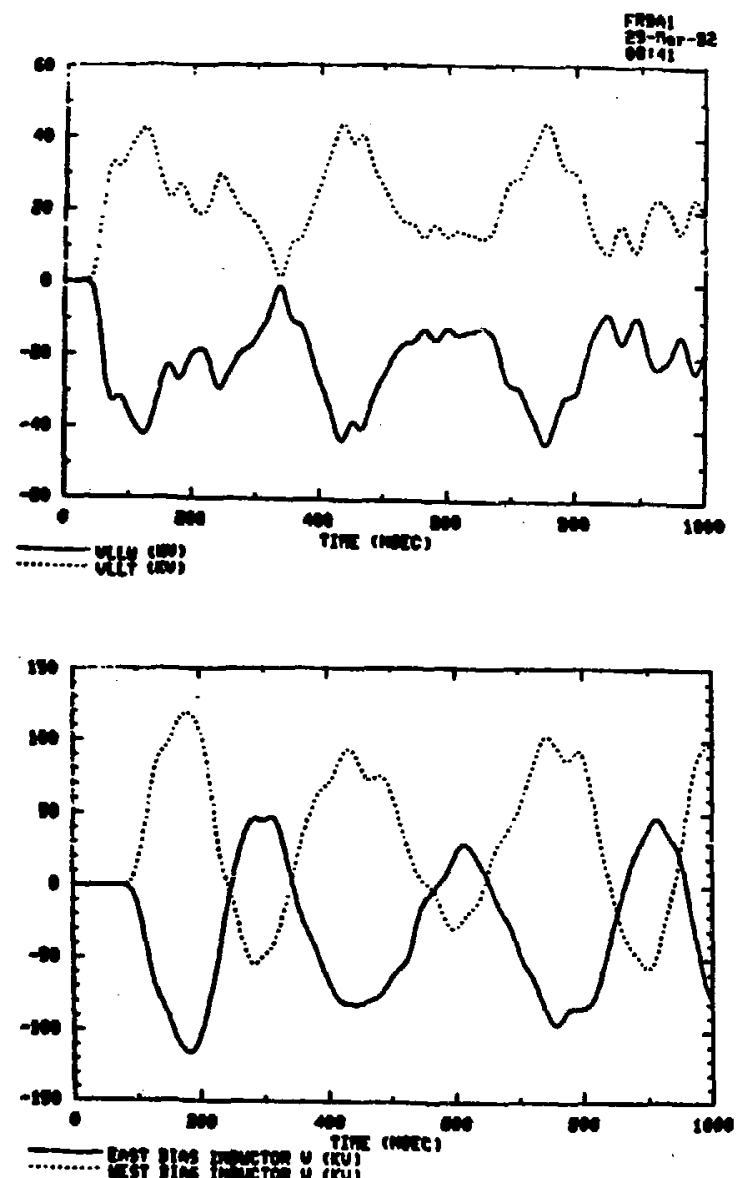

b)
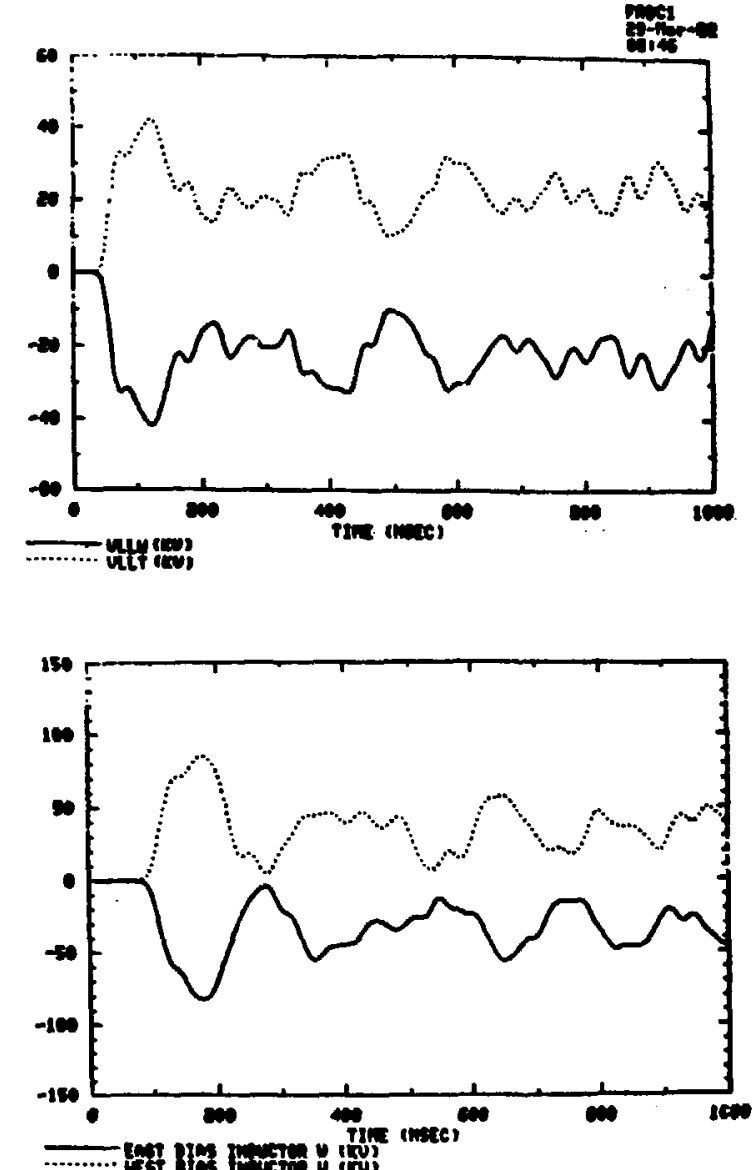

F1g. 12. Full benk calculations: load and bias Induetor coll voltages a) with no subbers; b) with noreal bias snubbers. 

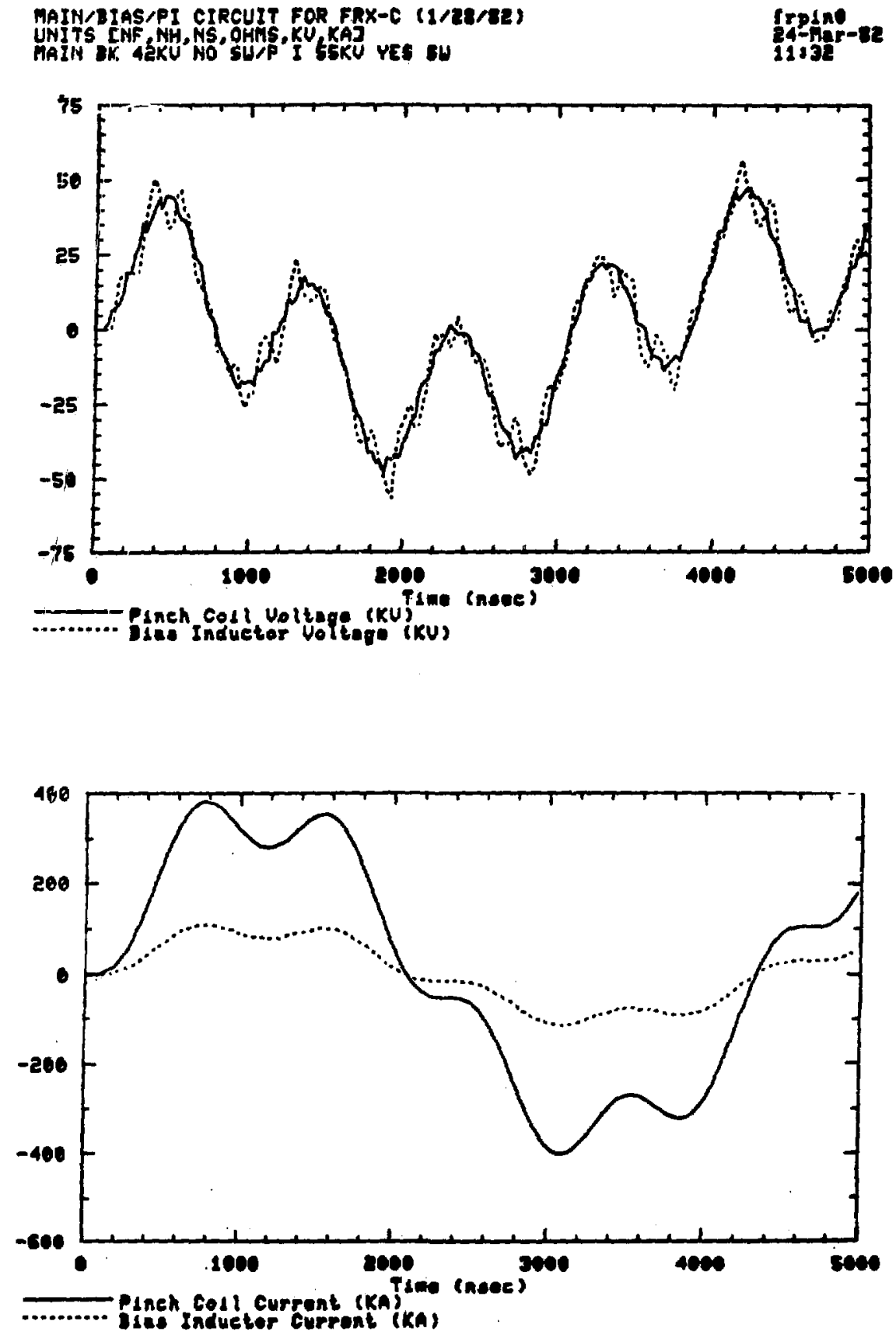

Fig. 13. $\theta$-pinch studies: 1oad coil and bias inductor voltages and currents calculated for a 55-kV PI-bank dlscharge. There are no snubbera or damping resistors. 


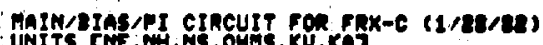

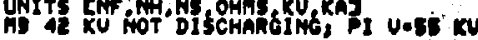
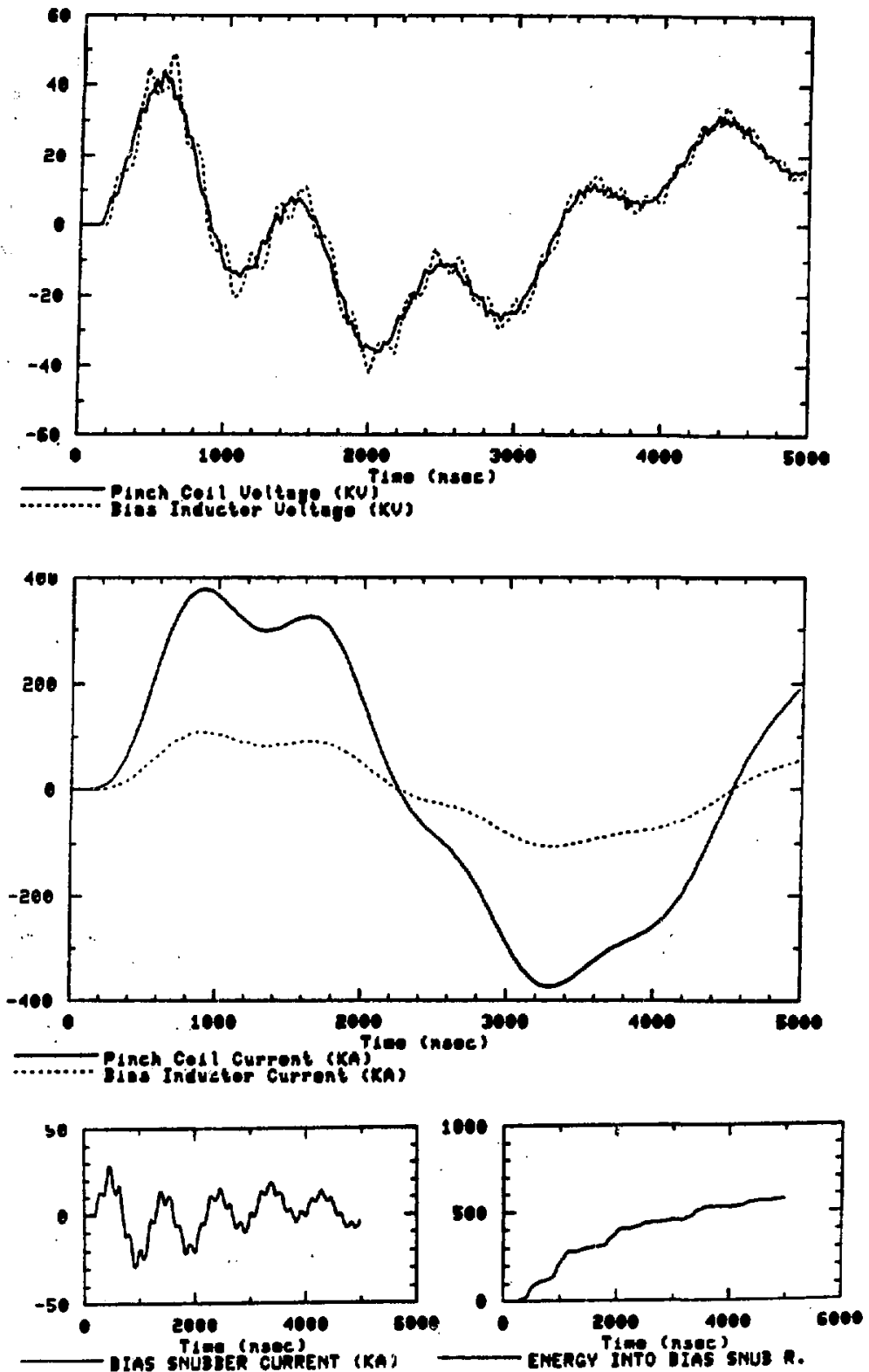

F1g. 14. Calculations for a 55-kV $\theta-P I$ discharge Including the normal blas Inductor snubber. 


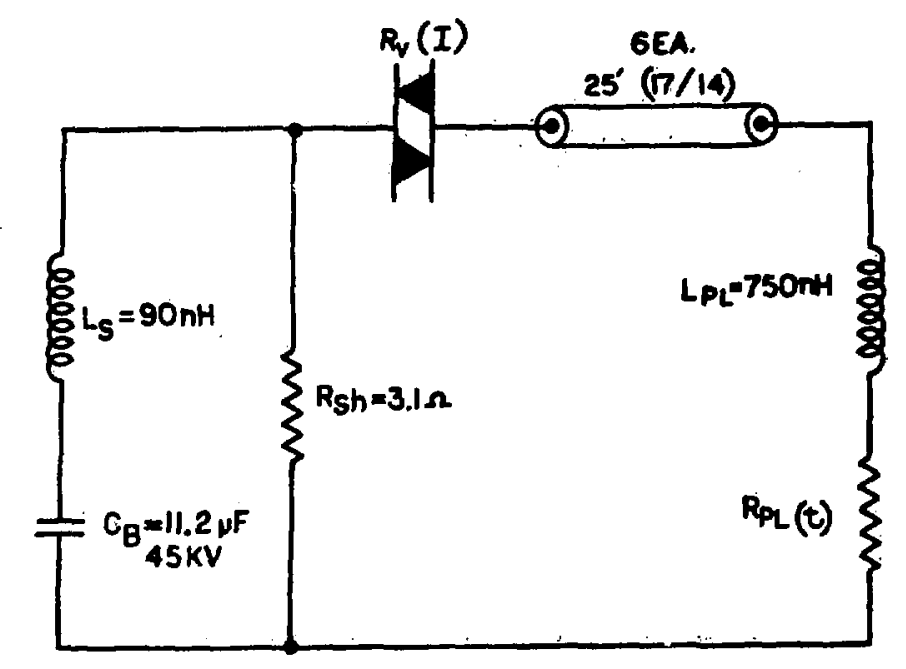

Fig. 15. Schematic diagram of z-pinch circuit.
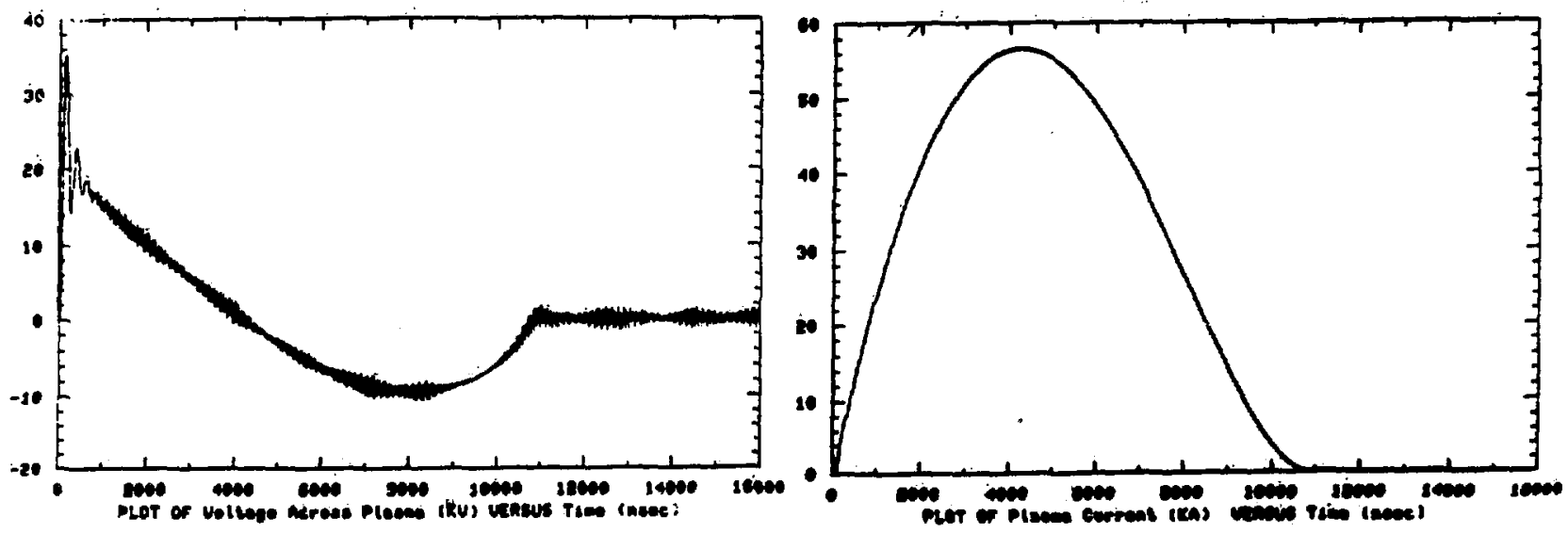

F18. 16. Calculated voltage and current for a z-pinch PI diacharge.

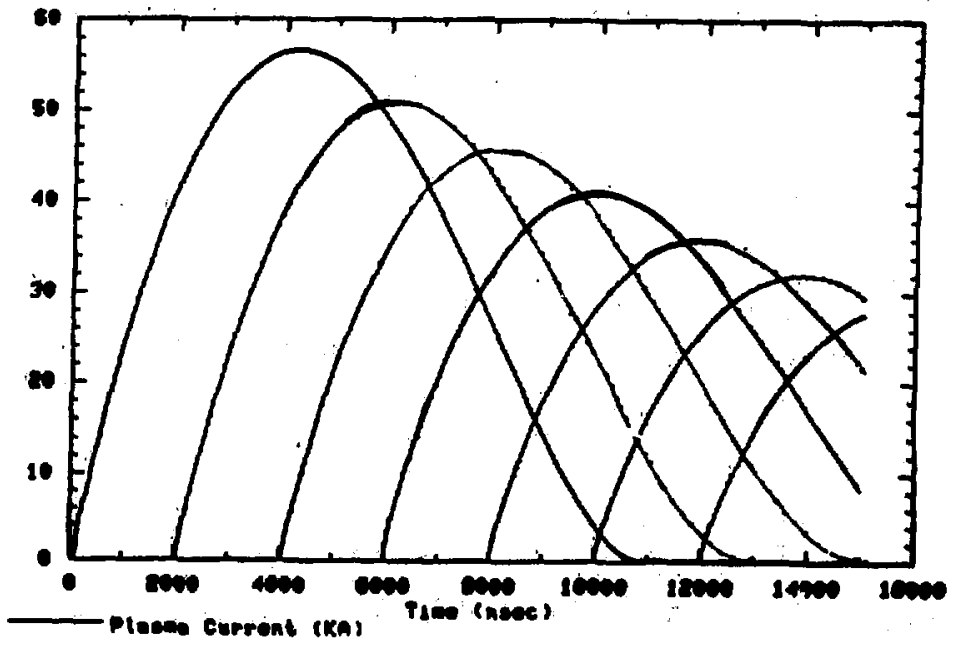

F1g. 17. Effect of delayed plase breakdoin on a z-pinch PI plase curtent. 